\title{
Escenarios para el sometimiento de excluidos de Justicia y Paz a la Jurisdicción Especial para la Paz: disquisición sobre sus ámbitos de aplicación
}

\author{
https://doi.org/10.22395/ojum.v17n35a5 \\ Carlos Felipe Rúa Delgado** \\ Tirson Mauricio Duarte Molina** \\ Luis Felipe Gómez Morales ${ }^{* * *}$
}

Recibido: 01 de octubre del 2018 • Aprobado: 25 de octubre del 2018

\begin{abstract}
RESUMEN
El primer intento de justicia transicional en Colombia se materializó con la Ley de Justicia y Paz (Ley 975 de 2005), en virtud del Acuerdo de Ralito entre las Autodefensas Unidas de Colombia y el gobierno colombiano. Posteriormente, con la expedición de la Ley 1592 de 2012, se generó la posibilidad de que los miembros que no cumplieran las condiciones establecidas en la Ley de Justicia y Paz o que no cumplieran con los compromisos adquiridos al someterse a dicha legislación, pudieran ser excluidos de ella y continuar siendo investigados y juzgados en la jurisdicción ordinaria. Como resultado del Acuerdo de Paz entre las Fuerzas Armadas Revolucionarias de Colombia y el gobierno colombiano, nació la Jurisdicción Especial para la Paz, mediante la cual se juzgarán los delitos cometidos durante el conflicto armado. El presente artículo pretende evaluar la posibilidad que tienen los excombatientes de grupos paramilitares que, habiéndose postulado a la Ley de Justicia y Paz y que hayan sido excluidos por no cumplir con algunos de los requisitos o por no haber cumplido con sus compromisos, puedan someterse a la Jurisdicción Especial para la Paz. Lo anterior se realiza a partir de la construcción de escenarios sobre casos icónicos de ex paramilitares excluidos de la Ley de Justicia y Paz.
\end{abstract}

Palabras clave: justicia transicional; justicia y paz; jurisdicción especial para la paz; exclusión.

Este artículo es producto del proyecto de investigación "Análisis de la función legislativa y la función judicial desde el marco del derecho internacional y la constitucionalización del derecho contemporáneo" de la Facultad de Derecho y Ciencia Política, del Grupo de Investigación Problemas Contemporáneos del Derecho y la Política (Gipcodep) de la Universidad de San Buenaventura, Cali, Colombia.

* Abogado, Universidad Santiago de Cali, Colombia y magíster en Educación Superior de la misma universidad. Doctorando en Ciencias Sociales y Jurídicas, Universidad Rey Juan Carlos, Madrid, España. Profesor de tiempo completo e investigador de la Universidad de San Buenaventura, Cali, Colombia. Líder del Grupo de Investigación Problemas Contemporáneos del Derecho y la Política (Gipcodep) de la Universidad de San Buenaventura, Cali, categoría A en Colciencias. Correo: cfrua@usbcali.edu.co Orcid: https://orcid.org/0000-0002-8915-8968

.*. Egresado de Derecho en la Universidad de San Buenaventura, Cali, Colombia. Actualmente inscrito en el curso MOOC "Corrección, estilo y variaciones de la lengua española" de la Universitat Autónoma de Barcelona, España. Coordinador del Semillero de Investigación Diaphanum de la Universidad de San Buenaventura, Cali, Colombia. Correo: subescritor@ gmail.com Orcid: https://orcid.org/0000-0002-6240-2609

.... Egresado de Derecho en la Universidad de San Buenaventura, Cali, Colombia. Miembro activo del Semillero de Investigación Diaphanum de la misma universidad. Correo: Ifgomezm91@gmail.com Orcid: https://orcid.org/0000-0001-5676-6441 


\title{
Submission Scenarios to the Special Jurisdiction for Peace for People Excluded from Ley de Justicia y Paz: Fields of Application Disquisition
}

\begin{abstract}
The first transitional justice attempt in Colombia was the Ley the Justicia y Paz (Law of Justice and Peace Law, Law 975 of 2005), as a result of the Ralito Agreement between the Autodefensas Unidas de Colombia and the Colombian government. Later on, with the issuance of Law 1592 of 2012, a possibility arose for excluding members who did not meet the conditions established in the Ley the Justicia y Paz or who did not comply with the commitments acquired by submitting to that legislation, and for them to continue being investigated and judged with the ordinary jurisdiction. As a result of the Peace Agreement between the Fuerzas Armadas Revolucionarias de Colombia (FARC-EP) and the Colombian government, the Special Jurisdiction for Peace (JEP) was founded, through which crimes committed during the armed conflict will be judged. This paper intends to evaluate the possibility for ex-combatants of paramilitary groups who, having applied for the Ley the Justicia y Paz and who were excluded for not fulfilling some of the requirements or for not having complied with their commitments, may submit to the JEP. The evaluation is done by constructing scenarios with iconic cases of former paramilitaries excluded from the the Ley the Justicia y Paz.
\end{abstract}

Keywords: transitional justice; Ley de Justicia y Paz; Special Jurisdiction for Peace; exclusion.

\section{Cenários para a submissão de excluídos de Justiça e Paz à Jurisdição Especial para a Paz: disquisição sobre seus âmbitos de aplicação}

\section{RESUMO}

A primeira tentativa de justiça transicional na Colômbia se materializou com a Lei de Justiça e Paz (Lei 975 de 2005), em virtude do Acordo de Ralito entre as Autodefesas Unidas da Colômbia e o governo colombiano. Posteriormente, com a expedição da Lei 1592 de 2012, criou-se a possibilidade de que os membros que não cumprissem com as condições estabelecidas na Lei de Justiça e Paz ou que não cumprissem com os compromissos adquiridos ao se submeter a tal legislação pudessem ser excluídos dela e continuar sob investigação e julgamento na jurisdição ordinária. Como resultado do Acordo de Paz entre as Forças Armadas Revolucionárias da Colômbia e o governo colombiano, nasceu a Jurisdição Especial para a Paz, por meio da qual serão julgados os delitos cometidos durante o conflito armado. O presente artigo pretende avaliar a possibilidade de que os ex-combatentes de grupos paramilitares que, depois de se postularem à Lei de Justiça e Paz e serem excluídos por não cumprirem com alguns dos requisitos ou por não cumprirem com seus compromissos, possam se submeter à Jurisdição Especial para a Paz. O anterior foi realizado a partir da construção de cenários sobre casos icônicos de ex-paramilitares excluídos da Lei de Justiça e Paz.

Palavras-chave: justiça transicional; justiça e paz; jurisdição especial para a paz; exclusão. 


\section{INTRODUCCIÓN}

La justicia transicional se ha convertido en la nueva forma de resolver los conflictos estatales. En ese sentido, la justicia transicional fue adoptada como paradigma en Colombia mediante la Ley 975 de 2005, conocida como Ley de Justicia y Paz, la cual consagró el cumplimiento de estándares en derechos humanos que permitían luchar contra la impunidad. Dicha norma fue expedida para darle soporte jurídico a la desmovilización de los grupos paramilitares que en ese momento habían firmado un acuerdo de paz con el Gobierno de Colombia, conocido como el Acuerdo de Ralito.

En palabras de la Corte Constitucional (2013b), con la promulgación de esta ley se quiso constituir un enorme esfuerzo político cuyo propósito fuese facilitar la reincorporación de miembros de grupos armados que estuviesen dispuestos a contribuir de manera efectiva a la consecución de la paz. De esta manera, nació en Colombia la Ley de Justicia y Paz como el primer mecanismo de justicia transicional. Ahora bien, dicho sistema sufrió mutaciones con la introducción de los criterios de priorización y exclusión. La primera se suscitó debido a que la infraestructura requerida para realizar las investigaciones y juzgamiento de los más de 32.500 desmovilizados y más de 417.000 hechos delictivos reportados (Unidad Nacional de Fiscalías para la Justicia y la Paz, 2013, p. 1) implicó un balance negativo con respecto a la eficacia de la ley.

Posteriormente, el legislador expidió la Ley 1592 de 2012 mediante la cual decidió que no todos los postulados a Justicia y Paz debían continuar con los beneficios consagrados en esa norma, en los casos en los que se incumplía con alguno de los compromisos adquiridos al momento de someterse a la misma o bien, cuando no cumplieran con los requisitos para poder postularse a la Ley 975 de 2005. Por esa vía se excluyó a varios ex combatientes de las Autodefensas Unidas de Colombia (AUC), entre los cuales se cuenta con algunos de los "cabecillas" de esa ex organización ilegal que pueden servir como referencia y que se analizan más adelante.

Por su parte, en el 2016 el Gobierno de Colombia suscribió, con el grupo armado Fuerzas Armadas Revolucionarias de Colombia-Ejército del Pueblo (FARC-EP), el Acuerdo de Paz, con el objetivo de dar fin al conflicto. Debido a esto, surgió la Jurisdicción Especial para la Paz (JEP,) establecida como el componente de justicia del Sistema Integral de Verdad, Justicia, Reparación y No Repetición. Se la adjudicó la función de administrar justicia transicional y conocer los delitos cometidos en el marco del conflicto armado con las FARC-EP cometidos antes del 1 de septiembre del 2016. Esta jurisdicción se creó con miras a satisfacer los derechos a la justicia de las víctimas, ofrecerles verdad y contribuir a su reparación, y de esta manera contribuir a la consecución de una paz estable y duradera.

Así las cosas, y sin olvidar que la existencia de la JEP se encuentra enmarcada en el juzgamiento de los delitos cometidos por los actores del conflicto armado 
en Colombia, se establece un cuestionamiento sobre la prevalencia de la Jurisdicción Especial frente a los posibles efectos de cosa juzgada que conlleva la exclusión del sistema de Justicia y Paz. De esta manera, para lo anterior resulta imperativo establecer los escenarios en los cuales se puede dar el sometimiento de los excluidos de Justicia y Paz a la Jurisdicción Especial para la Paz, teniendo en cuenta los elementos que dan origen a la exclusión, los ámbitos de aplicación y la eventual convergencia entre los dos sistemas para la postulación de miembros de los grupos paramilitares a la jurisdicción recién creada.

El propósito de este trabajo es reducir el umbral de incertidumbre con respecto a si una persona excluida de Justicia y Paz puede someterse a la Jurisdicción Especial para la Paz, a partir de la revisión de casos icónicos que pueden servir para establecer patrones de generalización con respecto a los demás excluidos.

\section{METODOLOGÍA}

Con el fin de reducir el umbral de incertidumbre en la decisión judicial y de aportar insumos que permitan resolver los cuestionamientos acerca de la posibilidad de que ex miembros excluidos de Justicia y Paz puedan someterse a la Jurisdicción Especial para la Paz, se plantean varios escenarios. Dichas situaciones hipotéticas parten de casos importantes de personas que fueron denominadas en su momento como comandantes o que presentaban algún rango de mando dentro de la estructura de las AUC.
Estos escenarios se construyen mediante la acción proyectiva, se tiene en cuenta cada posibilidad y el desarrollo futuro de cada caso, de esta manera se alcanza un soporte metodológico y epistémico (Londoño y Marín, 2002). A partir de los escenarios se analiza el fenómeno objeto del estudio desde un punto de vista retrospectivo y actual. Se emplean como variables los gestores del desarrollo del fenómeno, es decir, las dos jurisdicciones especiales, así como los factores que las determinan -las causales de exclusión y los ámbitos de aplicación de ambos sistemas-, para finalmente presentar los resultados en forma de escenarios (Cely, 1999).

En ese sentido, se deben establecer los conceptos claves de la metodología de los escenarios para posteriormente relacionar las variables que determinarán las posibilidades de realización de cada uno. Por ello, se hace necesario explicitar de qué se habla al utilizar el término de escenario cuando se describe un futuro posible y la forma de alcanzarlo, y por ende, la manera en que este es posible, deseable y realizable:

Tradicionalmente se han comprendido los escenarios posibles como todo aquello que se puede imaginar; los escenarios realizables como aquellos que son plausibles, en la medida en que las restricciones se eliminen; y, por último, los escenarios deseables se encuentran en algún lugar dentro de lo posible pero que no son todos necesariamente realizables (Maqueda, 1996). 
Como extensión de lo anterior, se encuentran que los escenarios posibles son los que se pueden imaginar sin importar si su posibilidad de ocurrencia es alta o baja; los deseables, a los cuales los sujetos desean llegar, también pueden ser calificados como los escenarios más convenientes en relación con las consecuencias; y los realizables son aquellos en los que la ocurrencia es factible en relación con las limitaciones de todas las demás posibilidades, es decir, todos los factores llevan a este futuro sin que necesariamente sea conveniente para los involucrados (Cely, 1999). Se advierte que los escenarios deseables forman parte de los escenarios posibles y no necesariamente son realizables (Maqueda, 1996; Cely, 1999).

Al respecto y con el fin de la construcción de los escenarios, se seleccionaron tres casos que tienen que ver con las causales primera, segunda y quinta establecidas en el artículo 5 de la Ley 1592 de 2012 que crea el artículo 11A de la Ley 975 de 2005 concernientes a los sujetos postulados y excluidos por: a) no pertenecer a los grupos armados al margen de la ley; b) incumplir los compromisos adquiridos al momento del sometimiento a dicha ley; y c) continuar con los actos delictivos después de haberse sometido al trámite de Justicia y Paz.

Posteriormente, se fijaron las variables que se aplicarán en dichos escenarios de acuerdo con lo presentado en párrafos antecedentes. La primera de las variables la constituyen las cinco causales de exclusión contempladas en la Ley 1592 de 2012, cada una de ellas identificadas por la letra X y un numeral en relación con la causal que representa. La segunda variable se determina con la constitución de los ámbitos de aplicación de la Jurisdicción Especial para la Paz, el ámbito personal se identifica con las letras A, B, C, D y E, proporcionales a la cantidad de posibilidades identificadas en la normatividad; a su vez, se acompañan con un numeral que enuncia una nueva variable que corresponde a la relación entre los ámbitos material y temporal, por lo que, de haber tres posibilidades en cuanto a materia y tiempo en relación con el ámbito A, este se extiende desde Al hasta A3.

Consecuentemente, las variables se distribuyen de acuerdo con el método de cadenas de razonamiento inductivo como forma de construcción de argumentos planteado por Vargas (2017) puesto que, a través de este, se logra construir un argumento a partir de un hecho y abarcar las posibilidades que se pueden alcanzar, he aquí la utilidad de la metodología de los escenarios: "estas probabilidades inductivas sí pueden ser comparadas. [...]. Esto permite pasar de la veracidad a la objetividad [...]" (Vargas, 2017, pp. 1028-1029). Se distribuirá, en este sentido, de la siguiente manera:

\begin{tabular}{|ccccccl|}
\hline X1 & X2 & X3 & X4 & X5 & X6 & Causales de exclusión (X) \\
& A & B & C & D & E & Ámbitos de Aplicación \\
Postulación JEP & No postulación JEP & Resultado \\
\hline
\end{tabular}


Como resultado, se obtendrá el escenario realizable de sometimiento o no; con lo cual se busca esclarecer las posibilidades de presentación de casos relevantes de exclusión del sistema de Justicia y Paz que han servido como precedente para otros casos similares, para que, de igual manera, se pueda sentar un nuevo precedente, pero con respecto a la Jurisdicción Especial para la Paz. En este sentido, por la importancia de los casos presentados sobre las causales relativas al incumplimiento de los compromisos adquiridos, hechos cometidos que estén relacionados con pertenencia a un grupo armado, cuando se haya sido condenado por delitos dolosos cometidos con posterioridad a su desmovilización, o cuando el postulado delinque estando privado de la libertad desde el centro de reclusión, y por la relevancia y trascendencia en el ámbito jurídico colombiano se seleccionaron los casos de Francisco Javier Zuluaga Lindo, Rodrigo Tovar Pupo y Daniel Rendón Herrera.

\section{SOBRE LA JUSTICIA TRANSICIONAL EN COLOMBIA}

La justicia transicional corresponde a un nuevo paradigma de resolución de conflictos que apareció después de la Segunda Guerra Mundial con los tribunales de Núremberg, pero que conceptualmente, tan solo sería definida por Teitel (2017). Las elaboraciones teóricas de la justicia transicional se han construido a partir de la garantía del restablecimiento democrático de sociedades que se encuentran en el paso de la terminación del conflicto y la recuperación de los derechos humanos, en aras de lograr un equilibrio que conlleve justicia y a la vez, una paz sostenible en el tiempo.

En ese sentido, Ambos (2009) establece que esta categoría se ocupa de la justicia en sociedades en transición, ya sea luego del conflicto o durante el curso de este; supone una serie de medidas que pueden ser de naturaleza judicial o no judicial. El éxito de esta depende del grado en que se contribuya con la verdadera reconciliación y consolidación de la democracia y el sistema judicial del Estado en el cual se lleve a cabo. Entonces, el elemento justicia en la justicia de transición se debe comprender de manera amplia: una idea de responsabilidad y equidad en la protección y vindicación de derechos y la prevención y castigo de infracciones (Ambos, 2009).

No obstante, se debe entender que la justicia transicional "es sobre todo y predominantemente justicia para las víctimas" (Ambos, 2009); ellas no solo tienen intereses en juego, sino también derechos como verdad, justicia y reparación. Por otra parte, Teitel (2002) plantea que la justicia transicional puede ser definida como la concepción de justicia que se encuentra asociada con los períodos de cambio político, caracterizados por respuestas legales que tienen el objetivo de enfrentar los crímenes cometidos por regímenes represores anteriores. Con todo, y en relación con la finalidad de esta justicia se ha dicho que los objetivos de la justicia de transición van: 
[...] desde el restablecimiento sicológico de las víctimas hasta la reconciliación nacional, y esto lo busca alcanzar a través de mecanismos de justicia penal, comisiones de la verdad, memoriales (que incluyen leyes de purificación, políticas de la memoria y pedidos de perdón públicos), y políticas de reparaciones a las víctimas. (Benavidez, 2010)

Por lo anterior, Rúa (2015) planteó que para el cumplimiento de estos fines es menester adoptar mecanismos que permitan resolver los problemas estructurales que se han heredado del conflicto. Aunado a ello, se hacen necesarios dos referentes en el contenido de la justicia transicional: uno político y uno normativo (Rúa, 2015). El primero se refiere a una transición, ya sea entre un conflicto y un posconflicto, el paso de un Estado autoritario a uno democrático, de una situación de graves violaciones a los derechos humanos a una de reconciliación (Rúa, 2015).

Por otro lado, el referente normativo implica que las normas de justicia transicional, especialmente las de carácter judicial, cumplan con los estándares internacionales en derechos humanos, sobre todo en materia de verdad, justicia, reparación y garantías de no repetición (Quinche, 2009; Valdivieso, 2012; Rúa, 2015).

Estos elementos se encuentran reflejados en la propuesta de construcción social de Osorio (2017), en la cual advierte que el inicio de esta se da con las transformaciones requeridas para que la violencia no se vuelva a suscitar, para que así el
Estado obtenga la capacidad de controlar y combatir los rezagos y nuevos brotes de terror. De allí que se deban adoptar medidas que busquen la protección y satisfacción de las víctimas tales como las ya mencionadas en el referente normativo de la justicia transicional, así como la reintegración y la reconciliación, en el entendido de que a través de ella se da: gobernabilidad territorial, cultura y educación para la paz (Ramírez, 2010) y la construcción de memoria histórica mediante el reconocimiento de la memoria alcanzada a través de la verdad (Rúa, 2016).

Así, la Corte Constitucional ha expuesto que la justicia transicional está constituida por un conjunto de procesos de transformación social y política profundos en los cuales es necesario utilizar mecanismos judiciales o extrajudiciales para resolver los problemas derivados de un pasado de abusos a gran escala, a fin de lograr que los responsables rindan cuentas de sus actos, servir a la justicia y lograr la reconciliación (Corte Constitucional, 2013a).

Lo expuesto hasta aquí se puede sintetizar con los planteamientos de Rúa (2016) cuando aborda el tema de la justicia transicional:

[...] corresponde al conjunto de elementos jurídicos, bien sean judiciales o extrajudiciales, determinados en acatamiento de los estándares internacionales definidos en materia de verdad, justicia, reparación y garantías de no repetición, mediante los 
cuales se pretende lograr un tránsito en uno de los siguientes supuestos: de un estado de vulneración sistemática de derechos humanos a uno de cesación de dicha vulneración, de un régimen totalitario a un régimen democrático o de un estado de conflicto a uno de cesación del conflicto, que implique la construcción de un posconflicto. (p. 458)

Así, mediante la Ley de Justicia y Paz, en cuanto al ámbito de la justicia transicional, el legislador adoptó una decisión de carácter político cuyo propósito fue facilitar la reincorporación de miembros de los grupos armados al margen de la ley dispuestos a contribuir de manera efectiva a la consecución de la paz. Para tal fin, se establecieron beneficios de tipo penal y un régimen específico y distinto de procedimiento penal -a cargo de autoridades judiciales especiales-, cuya interpretación y aplicación requiere de una valoración sistemática y armónica de sus instituciones (Corte Constitucional, 2013b). Esto es, en los términos expuestos por Patiño Yepes (2010), una justicia que medie para que las sociedades transiten de escenarios de conflicto armado con violaciones a derechos humanos e infracciones al derecho internacional humanitario a uno de paz, o de regímenes políticos dictatoriales a unos democráticos; lo anterior por medio de mecanismos participativos (Corte Constitucional, 2013b).

En este escenario de tránsito, la justicia transicional puede ser entendida como una rama de los derechos humanos con
"[...) enfoque pluridisciplinario, integral y holístico" (López, González y Errandonea, 2012); por ello sus métodos, marco teórico y herramientas pueden ser aplicados en democracias consolidadas, en las que se pretende reparar injusticias o violaciones a los derechos humanos ocurridas varias décadas o siglos atrás (López et al., 2012).

Se puede plantear, en el mismo sentido que Abuchaibe (2010), que la justicia transicional se ha convertido en uno de los elementos estructurales de reconstrucción de la sociedad colombiana con miras a la superación del conflicto armado. En suma, la justicia de transición involucra la incorporación de los derechos humanos como estándares de un modelo de justicia aplicable en circunstancias en las cuales se hace necesario el cambio de situación y que se involucren como medidas la verdad, la reparación y la no repetición, sin dejar de lado el intervalo entre cada extremo de la transición, y el hecho de que este se configura como un espacio de disputa entre los diferentes actores, intereses y discursos (Gómez Sánchez, 2014; Rúa, 2018).

De esta manera, la justicia transicional resulta indispensable para atender la terminación de un conflicto armado en la medida en que, sin desconocer la jurisdicción ordinaria, es necesaria la consecución de tribunales especiales que permitan que haya una construcción de verdad histórica, reparación a las víctimas, reconocimiento de la insurgencia, los agentes estatales y civiles como parte del conflicto y garantías duraderas para que 
no vuelva a escalar el conflicto. Por otro lado, la desmovilización de los integrantes de los grupos insurgentes, en aras de ofrecer unas prerrogativas que permitan su incorporación a la vida civil, implica que se deba ponderar la aplicabilidad de la sanción penal en su máxima expresión (no queriendo decir que deba aceptarse la impunidad como premisa) e integrar otros elementos que le dan relevancia especial a los sistemas de justicia transicional.

Por otro lado, la justicia transicional debe estar acompañada por un elemento de legitimidad que se afiance en el consenso y la participación ciudadana, que atienda a la reconstrucción de un orden afectado que ha de darse mediante un acuerdo participativo, justo y abierto (Mejía, 1998), como sucede con el acuerdo de paz con las FARC-EP, a pesar de sus apoyos y oposiciones. Asimismo, al construir y materializar el sistema de justicia transicional como medio para terminar el conflicto armado, no se busca que toda la sociedad deba estar de acuerdo, sino que se establezcan consensos mínimos que permitan la creación de un buen ciudadano y en un sentido más amplio, una mejor sociedad civil (Rúa y Castillo, 2015; Coral y Castillo, 2011).

\section{PROCEDENCIA Y EFECTOS DE LA EXCLUSIÓN EN JUSTICIA Y PAZ}

La desmovilización y reincorporación a la vida civil planteados en la Ley 975 de 2005 exigen una variedad de requisitos a quienes desean someterse a tal jurisdicción y adquirir la categoría de "postula- dos"; estos son: (i) que el desmovilizado entregue información o colabore con el desmantelamiento del grupo al que pertenecía; (ii) que haya suscrito un acta de compromiso con el Gobierno Nacional; (iii) que se haya desmovilizado y dejado las armas en los términos establecidos por el Gobierno Nacional para tal efecto; (iv) que cese toda actividad ilícita; y (v) que entregue los bienes producto de la actividad ilegal, para que se repare a las víctimas.

Lo anterior conlleva consecuencias a quien sea elegido como postulado, la imposición de diversas obligaciones por parte del Estado colombiano. Por lo tanto, en virtud de la ley transicional, el postulado se ve obligado a: (i) en aras de satisfacer la verdad, dar a conocer las circunstancias de tiempo, modo y lugar de los hechos delictivos en los cuales participó; (ii) en el marco de la obligación de justicia, permanecer privado de la libertad hasta que la autoridad competente así lo disponga, asistir a las audiencias, cumplir la sanción impuesta y los compromisos de comportamiento incluidos en el fallo; y (iii) en lo relacionado con el derecho a la reparación, entre otras obligaciones, entregar al Estado los bienes para la reparación de las víctimas (Seils, 2012).

Así, los criterios de priorización se pueden definir sin antes determinar criterios de selección. Es necesario tener claro que la selección es el género, mientras que la priorización es la especie, así lo explican Bergsmo y Saffon: 
Los criterios de selección sirven para determinar qué casos serán investigados y juzgados por una jurisdicción específica. [...] inevitablemente implican la deselección de ciertos casos. [...] los criterios de selección operan como un umbral por debajo del cual los casos no serán tratados por la jurisdicción en cuestión. [...] estos criterios normalmente consisten en un catálogo de elementos importantes que deben tenerse en cuenta al decidir si se va a ejercitar la jurisdicción. Y normalmente se aplican como si fueran una lista de control, en el sentido de que cuando un caso cumple con todos o con un número determinado de ellos califica para ser investigado y juzgado. (Bergsmo y Saffon, 2011)

Los criterios de prioridad, según los autores, sirven precisamente para clasificar los casos dentro de una jurisdicción, así como para determinar el orden en el que serán investigados y juzgados (Bergsmo y Saffon, 2011). Entonces, no se requiere una de-selección de los casos, dado que se pueden aplicar a los casos ya seleccionados o a casos que no han pasado por un filtro de criterios de selección, como es el caso de muchas jurisdicciones penales nacionales (Bergsmo y Saffon, 2011).

Además, los criterios de prioridad no operan como un umbral, ya que la totalidad de los casos clasificados deben ser finalmente investigados y perseguidos (Bergsmo y Saffon, 2011). Por lo anterior, queda claro que el establecer los criterios de selección y priorización ha correspondido a la respuesta de una necesidad; esta es, el salvaguardar la eficacia de la justicia, en general, y de la justicia transicional, en particular, como recurso efectivo ante la vulneración de derechos humanos (López, 2010; Rúa, 2014).

Consecuentemente, la Ley 1592 de 2012 introdujo la priorización y la exclusión como figuras para mejorar tal sistema. Respecto a la primera, el artículo 13 de esta ley reza que, con el fin de garantizar los derechos de las víctimas, se determinarán los criterios de priorización para el ejercicio de la acción penal, criterios que tendrán carácter y estarán dirigidos a esclarecer el patrón de macrocriminalidad en el accionar de los grupos armados organizados al margen de la ley, y a develar los contextos, las causas y los motivos de este, concentrando los esfuerzos de investigación en los máximos responsables.

Estos criterios de priorización y selección son entonces, una estrategia de juzgamiento de máximo responsable, además de señalar la posibilidad de renunciar a la persecución judicial, penas alternativas, suspensión en la ejecución de las penas y penas extrajudiciales (Rúa, 2015). Entonces:

[...] queda claro que el establecimiento de criterios de selección y priorización corresponde a una necesidad para salvaguardar la eficacia de la justicia, en general, y de la justicia transicional, en particular, como recurso efectivo ante los casos de vulneración de derechos humanos, máxime en un conflicto de décadas como el colombiano. (Rúa, 2014) 
Ahora, respecto a la figura de la exclusión, la Corte Constitucional (2013b) la ha definido como el mecanismo a través del cual la autoridad judicial de conocimiento del proceso de Justicia y Paz - previa solicitud de la Fiscalía- expulsa al postulado. Por su parte, la Corte Suprema de Justicia (2009c) ha precisado que esta figura opera cuando el postulado no cumple con los requisitos generales y los objetivos establecidos en la Ley 975 de 2005 para su vinculación al trámite especial, o cuando en el curso del proceso o dentro de la ejecución de la pena alternativa, incumple con las obligaciones propias de su condición. Concordante con lo anterior se halla el artículo 5 de la Ley 1592 de 2012, la norma en la que se consagran las causales de exclusión $\left(\mathrm{X}^{1}\right)$, a saber:

(I) Cuando el postulado sea renuente a comparecer al proceso o incumpla los compromisos propios de la presente ley (X1),

(II) Cuando se verifique que el postulado ha incumplido alguno de los requisitos de elegibilidad establecidos en la presente ley (X2),

(III) Cuando se verifique que el postulado no haya entregado, ofrecido o denunciado bienes adquiridos por él o por el grupo armado organizado al margen de la ley durante y con ocasión de su pertenencia al mismo,

\footnotetext{
En el listado de causales de exclusión se identifica a cada una con la letra X y el numeral al que corresponden con el fin de identificar de mejor manera y lograr establecer los escenarios realizables de postulación a la Jurisdicción Especial para la Paz.
}

de forma directa o por interpuesta persona (X3),

(IV) Cuando ninguno de los hechos confesados por el postulado haya sido cometido durante y con ocasión de su pertenencia a un grupo armado organizado al margen de la ley (X4),

(V) Cuando el postulado haya sido condenado por delitos dolosos cometidos con posterioridad a su desmovilización, o cuando habiendo sido postulado estando privado de la libertad, se compruebe que ha delinquido desde el centro de reclusión (X5),

(VI) Cuando el postulado incumpla las condiciones impuestas en la audiencia de sustitución de la medida de aseguramiento de que trata el artículo 18A de la presente ley (X6).

Tiene la exclusión -como propósito específico- buscar una mayor efectividad del proceso sobre la base de unificar criterios y brindar confianza a los operadores jurídicos en sus decisiones, y enfocarse en las personas que en realidad estuvieren dispuestas a cumplir con los requisitos de elegibilidad, y a contribuir con la reconstrucción de la paz (Corte Suprema de Justicia, 2009b). De esta manera, si la solicitud se considera procedente se podrá declarar la terminación del proceso y se dispondrá el envío de copia de la actuación a la autoridad judicial competente, para que esta adelante las respectivas investigaciones (Corte Constitucional, 2015). 
Es preciso recalcar que la figura de la exclusión no representa un pronunciamiento de fondo en relación con los delitos confesados por el postulado en su versión libre y objeto del proceso de Justicia y Paz; lo anterior como consecuencia de que la investigación y juzgamiento correrá eventualmente a cargo de la justicia ordinaria (Corte Suprema de Justicia, 2009a).

La decisión que excluye a los postulados de Justicia y Paz se tomará mediante auto, contra el cual procederá el recurso de apelación ante la Sala Penal de la Corte Suprema de Justicia, según lo establecido en el artículo 26 de la Ley 975 de 2005. No obstante, aun cuando el postulado se encuentre excluido de la jurisdicción esta no implica la pérdida de los derechos de las víctimas puesto que la justicia ordinaria, donde se seguirá realizando la investigación, deberá salvaguardarlo (Corte Suprema de Justicia, 2012).

Es en virtud de lo anterior que se logra determinar que la exclusión del sistema de Justicia y Paz no conlleva propiamente que se dé el tránsito a cosa juzgada; esto en virtud de lo establecido por la Corte Suprema de Justicia y la Corte Constitucional al sostener -en repetidas ocasione-s que el principio de cosa juzgada no es de carácter absoluto, ya que puede ser limitado para que se defiendan bienes de supremo valor como: el derecho de los procesados o de las víctimas de violaciones a los derechos humanos o graves infracciones al derecho internacional humanitario (Corte Constitucional, 2003a; Corte Constitucional, 2003b; Corte
Suprema de Justicia, 2016). El proceso adelantado por la Ley de Justicia y Paz no es ajeno al funcionamiento de tal principio debido a que se nutre de las garantías otorgadas por el ordenamiento colombiano entre las cuales se incluye, y además con un lugar sobresaliente, la prohibición de doble juzgamiento.

Aunado a lo anterior, se desvirtúa la operatividad de la cosa juzgada respecto de la exclusión de la Ley de Justicia y Paz mediante el inciso 3 del artículo 11 A de la Ley 975 de 2005, en el cual se establece que una vez se encuentre en firme la decisión del proceso en virtud de la exclusión, se compulsarán copias a la autoridad judicial competente para que se adelante la investigación respectiva. Lo anterior ocasiona que el juez de Justicia y Paz pierda competencia sobre el asunto, y esta sea adquirida por la justicia ordinaria. Competencia que puede ser atribuida a otras jurisdicciones, como se verá en el siguiente acápite.

Se puede determinar que la figura de la exclusión es de gran relevancia por cuanto, en el sentido que expresa la Corte Suprema de Justicia, al descartar a los postulados de recibir los beneficios de esta jurisdicción, al no cumplir con los requisitos generales establecidos, se está permitiendo la celeridad en los procesos de otros postulados que han llevado a cabalidad los obligaciones contenidas y que los hace acreedores de los beneficios contemplados, además de satisfacer los derechos de verdad, justicia y reparación de las víctimas (Corte Suprema de Justicia, 2009a). 


\section{SOMETIMIENTO A LA JURISDICCIÓN ESPECIAL PARA LA PAZ: PRINCIPIOS, INSTRUMENTOS Y ÁMBITOS DE APLICACIÓN}

Se puede establecer que, si bien es cierto que Justicia y Paz podría tener un sesgo hacia lo militar, esto es: hacia los miembros de grupos armados ilegales que hubieren desempeñado funciones militares dentro del conflicto; por otra parte, la Jurisdicción Especial para la Paz se ha estructurado sobre la base de que los terceros que hubiesen cumplido diferentes roles dentro del mismo se pueden presentar voluntariamente ante la misma con el fin de contribuir a la paz y la reconciliación.

De manera consecuente, el literal h) del artículo 76 del mismo Proyecto de Ley Estatutaria de la Jurisdicción Especial para la Paz señala que dentro de las funciones de la Sala de Definición de Situaciones Jurídicas se encuentra el definir la situación de quienes no hayan tenido una participación determinante en los casos más graves y representativos, en particular respecto de las conductas a las que se refiere el artículo 23 de la Ley 1820 de 2016, que incluye:

[...] la definición de la situación jurídica de aquellos terceros que se presenten voluntariamente a la jurisdicción en los 3 años siguientes de su puesta en marcha y que tengan procesos o condenas por delitos que son competencia de la JEP, cuando no hayan tenido una participación determinante en los delitos más graves y representativos. Una vez verificada la situación jurídica, adoptará las resoluciones necesarias, entre otras la renuncia a la acción penal u otro tipo de terminación anticipada al proceso, siempre que contribuyan de manera eficaz a las medidas del SIVJRNR [...] (Congreso de la República, s.f.)

Esta atribución de competencias se da con base en el principio de tratamiento equitativo que regula a esta jurisdicción y se encuentra definido expresamente en el artículo 62 de su proyecto de Ley Estatutaria, en el cual se expresa que el trato que se debe dar a los integrantes de las FARC-EP "[...] puede ser diferente pero equilibrado y equitativo" respecto a los agentes del Estado, y de igual manera, para quienes hayan participado en el conflicto, siendo o no combatientes.

En tal sentido, ha sido la Corte Suprema de Justicia (2017a) la que, siguiendo trazos argumentativos similares y, en virtud de estas normas, señaló que no se puede dar una interpretación fragmentada de la normatividad, por cuanto se puede presentar una omisión al considerar diversos destinatarios de la Ley 1820 de 2016, normativa expedida en desarrollo del Acuerdo final para la terminación del conflicto armado y la construcción de una paz estable $y$ duradera, suscrito entre el grupo guerrillero FARC-EP y el Gobierno Nacional. Y respecto al cual la Corte Suprema de Justicia resalta su ámbito de aplicación al exponer que:

Su ámbito de aplicación, de acuerdo con el artículo $3^{\circ}$, se contrae a todos quienes, ha- 
biendo participado de manera directa o indirecta en el conflicto armado, hayan sido condenados, procesados o señalados de cometer conductas punibles por causa, con ocasión o en relación directa o indirecta con el conflicto armado cometidas con anterioridad a la entrada en vigor del acuerdo final. También cobijará conductas amnistiables estrechamente vinculadas al proceso de dejación de armas. (Corte Suprema de Justicia, 2017a)

Entonces, según lo planteado por esta Corporación, son varios los destinatarios de los tratamientos penales especiales diferenciados; resalta a quienes participaron de manera directa o indirecta dentro del conflicto armado y fueron condenados, procesados o señalados de cometer conductas punibles por causa, con ocasión o en relación directa o indirecta con el conflicto armado, cometidas con anterioridad a la entrada en vigor del acuerdo final (Corte Suprema de Justicia, 2017a). Lo anterior en virtud del principio de buena fe, pues a pesar de que estos actores han incumplido en una jurisdicción, este precepto implica la consideración del buen actuar del postulado al nuevo sistema de justicia; y es en este sentido que la Corte Constitucional (2004) ha dicho que la buena fe incorpora el valor ético de la confianza y significa que el hombre cree y confía que una declaración de voluntad surtirá, en un caso concreto, sus efectos usuales, es decir, los mismos que ordinaria y normalmente ha producido en casos análogos.
No obstante, se debe tener en cuenta un precepto que se encuentra íntimamente ligado al principio de buena fe, este es, la confianza legítima. La Corte Constitucional (2011) sostuvo que el principio de buena fe, en su dimensión de confianza legítima, puede ser amenazado en cuanto sea inobservado por parte de las autoridades, ya que se podría vulnerar el derecho fundamental al debido proceso; este comprende la garantía que las decisiones proferidas durante un proceso se harán sobre las reglas de juego establecidas previamente.

Además, lo planteado se encuentra estrechamente relacionado con el principio de igualdad; respecto al cual la misma Corporación ha dicho que es transversal a toda la actividad estatal, y que como derecho comprende dos garantías fundamentales: (I) la igualdad ante ley y (II) la igualdad de protección y trato ante las autoridades. Empero, ambas garantías operan de manera conjunta en lo que concierne a la actividad judicial, por lo que "en lo que respecta a la actividad judicial, la igualdad de trato que las autoridades deben otorgar a las personas supone además una igualdad en la interpretación y en la aplicación de la ley" (Corte Constitucional, 2011).

De esta manera, y en relación con los principios aplicables dentro del procedimiento de la Jurisdicción Especial para la Paz, el artículo 4 de la Ley 1820 de 2016 contempla que se dará aplicación de los principios contenidos en el acuerdo de creación de tal jurisdicción en el marco 
del fin del conflicto, con respecto a la amnistía, el indulto y otros mecanismos penales especiales diferenciados de extinción de responsabilidades y sanciones penales principales y accesorias también, se aplicarán con respecto a todas las sanciones administrativas, disciplinarias, fiscales o renuncia del Estado al ejercicio de la acción penal.

Por otra parte, el artículo transitorio 6 del Acto Legislativo 1 de 2017 consagra un principio de vital importancia al momento de tener en cuenta los ámbitos de aplicación de la Jurisdicción Especial para la Paz, pues establece que esta jurisdicción prevalecerá sobre las actuaciones penales, disciplinarias o administrativas por conductas cometidas con ocasión, por causa o en relación directa o indirecta con el conflicto armado, al absorber la competencia exclusiva sobre dichas conductas.

En correlación con todo lo anterior, el artículo 6 de la Ley 1820 de 2016 exhorta a la integralidad en la aplicación de lo pactado en el Acuerdo de Paz y los tratamientos de la Jurisdicción Especial para la Paz al plasmar las amnistías e indultos, y los tratamientos penales especiales, incluidos los diferenciados para agentes del Estado. Son medidas cuyos fines esenciales son facilitar la terminación del conflicto armado interno, contribuir al logro de la paz estable y duradera con garantías de no repetición, adoptar decisiones que otorguen plena seguridad jurídica para todos y satisfacer los derechos de las víctimas. Por ello, los distintos componentes y medidas están interconectados a través de mecanismos, garantías, requisitos para acceder y mantener los tratamientos especiales de justicia en la naciente jurisdicción.

Es por ello que se debe realizar un análisis de la normatividad expuesta hasta el momento de manera holística y concordante, y atender al artículo 7 de la Ley 1820 de 2016, en el cual se contempla el principio de prevalencia en el mismo sentido que el Acto Legislativo 1 de 2017:
Las amnistías, indultos y los tratamientos penales tales como la extinción de responsabili- dades y sanciones penales y administrativas o renuncia del Estado a la persecución penal [...] prevalecerán sobre las actua- ciones de cualquier jurisdicción o procedimiento, en especial sobre actuaciones penales, discipli- narias, administrativas, fiscales o de cualquier otro tipo, por conductas ocurridas en el marco del conflicto interno, por causa, con ocasión o en relación directa o indirecta a este.

Este principio también se encuentra contemplado en el artículo 31 del Proyecto de Ley Estatutaria al plasmar que esta jurisdicción en relación con lo establecido en el Acuerdo Final prevalecerá sobre las actuaciones penales, disciplinarias, fiscales o administrativas por conductas cometidas con ocasión, por causa y en relación directa o indirecta con el conflicto armado, al absorber la competencia exclusiva sobre dichas conductas (Congreso de la República, s.f.). 
Y, de manera concordante, el artículo 38 de la Ley 1820 contempla:

\begin{abstract}
ARTíCULO 38. Todo lo previsto en esta ley será de aplicación para las personas, conductas, delitos y situaciones en ella prevista, cualquiera que sea la jurisdicción ante la cual hayan sido condenados, estén siendo investigados o procesados.
\end{abstract}

En virtud de lo anterior, y especialmente del principio de prevalencia, la Corte Constitucional ha dicho que se ajusta a la Carta Política y al escenario de la transición, puesto que el objetivo central de esta jurisdicción es concentrar el estudio de los casos asociados al conflicto armado, para observarlos desde una perspectiva integral que contribuya a conocer las causas profundas del conflicto, y a la consecución de la verdad, derecho de las víctimas y aspiración general de la sociedad colombiana, y por lo tanto, es menester que sus decisiones prevalezcan sobre las de otras jurisdicciones desde el enfoque holístico del Sistema Integral de Verdad, Justicia, Reparación y No Repetición (Corte Constitucional, 2018).

Por su parte y en esta línea argumentativa, la Corte Suprema de Justicia expuso que el ámbito de aplicación y el universo de destinatarios derivados del Acuerdo de Paz y la Ley 1820 de 2016 poseen un carácter incluyente antes que restrictivo o restringido exclusivamente a los integrantes reconocidos de las FARC-EP (Corte Suprema de Justicia. 2017b). Empero, con la claridad sobre los principios bajo los cuales se debe regir el sometimiento de actores del conflicto a la Jurisdicción Especial para la Paz, se hace necesario determinar los ámbitos en los cuales estos actores podrían acceder. Para el desarrollo de lo anterior se debe entender el contenido de los tres ámbitos: personal, material y temporal (Corte Constitucional, 2018).

Así pues, el ámbito personal hace referencia a las personas que podrán ser beneficiadas por amnistías, indultos y tratamientos penales especiales previstos; el ámbito de aplicación temporal se refiere a conductas cometidas antes de la celebración del acuerdo, y excepcionalmente durante el proceso de dejación de armas de las FARC-EP; el ámbito material se proyecta en dos direcciones: a conductas ocurridas durante el conflicto armado interno y a hechos delictivos ocurridos en disturbios públicos o en la protesta social (Corte Constitucional, 2018).

\section{ESCENARIOS DE PREVALENCIA DE LA JURISDICCIÓN ESPECIAL PARA LA PAZ}

En el desarrollo del presente acápite se plantearán tres casos específicos en los cuales se excluyó de Justicia y Paz a tres postulados. Se abordará, en tal sentido, la manera a través de la cual podrían acceder a los beneficios de la Jurisdicción Especial para la Paz, teniendo en cuenta las causales de exclusión de la primera jurisdicción (X) y los ámbitos de aplicación de la segunda (A - E). Dentro de los presupuestos para cada uno de los siguientes casos, se encuentra que, para 
Escenarios para el sometimiento de excluidos de Justicia y Paz a la Jurisdicción Especial para la Paz: disquisición ...

Tabla 1. Ámbitos de aplicación de la Jurisdicción Especial para la Paz

\begin{tabular}{|c|c|c|c|}
\hline Ámbito personal & $I d^{*}$ & Ámbito material & Ámbito temporal \\
\hline \multirow{2}{*}{$\begin{array}{l}\text { Ex miembros de las FARC- } \\
\text { EP }\end{array}$} & $\mathrm{Al}$ & $\begin{array}{l}\text { Conductas ocurridas con ocasión, } \\
\text { por causa, en relación directa o en } \\
\text { relación indirecta con el conflicto. }\end{array}$ & $\begin{array}{l}\text { Hechos que tuvieron lugar antes de } \\
\text { la entrada en vigor del Acuerdo Final. }\end{array}$ \\
\hline & A2 & $\begin{array}{l}\text { Conductas ocurridas en relación con } \\
\text { el proceso de dejación de armas. }\end{array}$ & $\begin{array}{l}\text { Conductas ocurridas durante el } \\
\text { proceso de dejación de armas. }\end{array}$ \\
\hline $\begin{array}{l}\text { Agentes del Estado que } \\
\text { son miembros de la Fuerza } \\
\text { Pública }\end{array}$ & B & $\begin{array}{l}\text { Delitos cometidos con ocasión, } \\
\text { por causa, en relación directa o en } \\
\text { relación indirecta con el conflicto } \\
\text { armado, con excepción de los que } \\
\text { son propios del servicio militar y de } \\
\text { conocimiento de la Justicia Penal } \\
\text { Militar. }\end{array}$ & $\begin{array}{l}\text { Conductas ocurridas antes de la } \\
\text { entrada en vigor del Acuerdo Final. }\end{array}$ \\
\hline \multirow{2}{*}{$\begin{array}{l}\text { Agentes del Estado distin- } \\
\text { tos a los miembros de la } \\
\text { Fuerza Pública }\end{array}$} & $\mathrm{Cl}$ & $\begin{array}{l}\text { Acudirán voluntariamente a la JEP } \\
\text { (C-674 de 2017) }\end{array}$ & \multirow[b]{2}{*}{$\begin{array}{l}\text { Hechos ocurridos antes de la entrada } \\
\text { en vigor del Acuerdo Final. }\end{array}$} \\
\hline & $\mathrm{C} 2$ & $\begin{array}{l}\text { Conductas ocurridas con ocasión, } \\
\text { por causa, en relación directa o } \\
\text { indirecta con el conflicto armado. }\end{array}$ & \\
\hline \multirow{2}{*}{$\begin{array}{l}\text { Terceros que tuvieron par- } \\
\text { ticipación en el conflicto } \\
\text { (colaboradores o finan- } \\
\text { ciadores) }\end{array}$} & D1 & $\begin{array}{l}\text { Acudirán voluntariamente a la JEP } \\
\text { (C-674 de 2017) }\end{array}$ & \multirow{2}{*}{$\begin{array}{l}\text { Hechos ocurridos antes de la entrada } \\
\text { en vigor del Acuerdo Final. }\end{array}$} \\
\hline & D2 & $\begin{array}{l}\text { Conductas ocurridas con ocasión, } \\
\text { por causa, en relación directa o } \\
\text { indirecta con el conflicto armado. }\end{array}$ & \\
\hline \multirow{4}{*}{$\begin{array}{l}\text { Personas que incurrieron } \\
\text { en conductas punibles } \\
\text { en el marco de protestas } \\
\text { sociales o en disturbios } \\
\text { públicos. }\end{array}$} & $\mathrm{El}$ & $\begin{array}{l}\text { Acudirán a la JEP voluntariamente o a } \\
\text { través de organizaciones de defensa } \\
\text { de derechos humanos. }\end{array}$ & \multirow{4}{*}{$\begin{array}{l}\text { Conductas que tuvieron lugar antes } \\
\text { de la entrada en vigor del Acuerdo } \\
\text { Final. }\end{array}$} \\
\hline & E2 & $\begin{array}{l}\text { Conductas relacionadas con dis- } \\
\text { turbios públicos (eventualmente } \\
\text { asonada). }\end{array}$ & \\
\hline & E3 & $\begin{array}{l}\text { Hechos punibles ocurridos durante } \\
\text { protestas sociales. }\end{array}$ & \\
\hline & E4 & $\begin{array}{l}\text { En todos los casos se tomarán en } \\
\text { cuenta los delitos conexos definidos } \\
\text { en los artículos } 24 \text { y } 28 \text {, numeral } 8 \\
\text { de esta Ley. }\end{array}$ & \\
\hline
\end{tabular}

- La clave representada en esta columna corresponde a la identificación de cada ámbito de aplicación a través del cual se podría evidenciar el escenario deseable para la postulación a la Jurisdicción Especial para la Paz.

Fuente: elaboración propia tomando como base el artículo 3 de la Ley 1820 de 2016, artículos transitorios 16 y 17 del Acto Legislativo 1 de 2017, y las sentencias C-674 de 2017 y C-007 de 201 
cada actor-excluido, el escenario deseable es la postulación al sistema de justicia planteado por la Jurisdicción Especial para la Paz.

\subsection{Escenario N. ․ 1. Postulados excluidos de Justicia y Paz por no pertenecer a grupos armados al margen de la ley}

Cuando el Congreso expidió la Ley de Justicia y Paz, se pensó que los beneficios del régimen de la justicia transicional debían ser efectivamente para los miembros de los grupos armados al margen de la ley, en este caso las Autodefensas Unidas de Colombia. En ese sentido, como los paramilitares eran los destinatarios directos de la norma, los presuntos terceros colaboradores del conflicto armado debían sujetarse al régimen establecido en la jurisdicción ordinaria. Lo anterior no quiere decir que los terceros no cometieron conductas punibles únicamente relacionadas con el conflicto, sino que, por el contrario, se podían estar cometiendo otra clase de delitos como el narcotráfico, o varios en conjunto para constituir el concierto para delinquir.

Así pues, en el desarrollo de este sistema se hizo evidente que hubo personas que se postularon como integrantes de alguno de los bloques de las autodefensas y como en el curso de la investigación no fue posible corroborar la pertenencia del postulado al grupo armado, se procedió a la exclusión de Justicia y Paz, para que la competencia la tuvieran nuevamente los jueces penales ordinarios. Ahora bien, la ley 975 de 2005 no contemplaba las causales de exclusión en su texto original y fue hasta que se expidió la ley 1592 de 2012 que se establecieron los presupuestos procesales para solicitar la exclusión del postulado ante el magistrado con función de control de garantías.

Por su parte, se tiene que en las sentencias de exclusión se puede apreciar que la Corte Suprema de Justicia en su sala de Casación Penal, afirma que los excluidos han participado en el conflicto armado, pero como no pertenecen en el sentido estricto a la estructura armada, deben ser excluidos del sistema transicional, dado que la norma no contempla el sometimiento de terceros partícipes en el conflicto. En ese orden de ideas, para analizar el escenario en concreto se tomará la exclusión de Francisco Javier Zuluaga Lindo.

El postulado fue excluido de los beneficios de la Ley de Justicia y Paz a partir de la investigación realizada por la Fiscalía General de la Nación, desde el momento en que se hizo efectiva la desmovilización y/o postulación del procesado del Bloque Héroes del Chocó. En el curso de la investigación, el ente acusador realizó el emplazamiento a las víctimas, surtiéndose a la vez las diligencias de versión libre. No obstante, el ente acusador presentó la solicitud de exclusión con base en los numerales 2 y 5 del artículo 5 de la ley 1592 de 2012 (X2 y X4). Para la Fiscalía si bien, el postulado había cometido delitos, no había forma de relacionarlos como consecuencias de la participación directa 
en el Bloque Héroes del Chocó de las Autodefensas, por lo cual debía proceder su exclusión (X4).

En ese orden de ideas, la Fiscalía realizó una evaluación de los elementos probatorios tenidos hasta la fecha, en la que resaltan que una cosa es la alianza entre los paramilitares y los narcotraficantes para financiar actividades concernientes al desarrollo del conflicto armado y otra, haber pertenecido en esencia a las Autodefensas Unidas de Colombia a través de sus bloques. De esta manera, la causal de exclusión se centra en que la actividad delictiva era el narcotráfico y no el concierto para delinquir derivado de la pertenencia a grupos armados al margen de la ley (D1 y D2). Por otro lado, dicha exclusión se apoyó en el testimonio de Ever Veloza, Salvatore Mancuso y Edwar Cobos quienes manifestaron que Zuluaga Lindo no perteneció a las autodefensas, sino que fue un financiador del grupo armado ilegal a través del "gramaje" para poder sacar la droga del país.

Como corolario, se tiene que la exclusión de este sistema se dio en dos partes: el primero por parte del Tribunal Superior de Distrito Judicial de Medellín y la Corte Suprema de Justicia. Sobre el primero el Tribunal Superior de Distrito Judicial de Medellín (2013) expuso que no se discute el ejercicio de actividades criminales de Zuluaga Lindo como narcotraficante y que, en ese sentido, haya sido financiador del bloque Calima de las AUC, ni siquiera sus relaciones con los hermanos Castaño
Gil, sino que su condición era de un financiador, no de un miembro del grupo armado o que perteneciera a la estructura de mando; debía proceder la exclusión porque su participación es como un civil en el conflicto, no como un paramilitar. Por su parte, la Corte Suprema de Justicia (2014) ratificó la posición del Tribunal en la medida en que Gordo lindo fue un financiador del conflicto, no un integrante de las autodefensas.

Se observa entonces que la exclusión de Zuluaga Lindo se dio por no pertenecer al grupo armado beneficiario de la Ley 975, por lo que este sistema procesal de justicia transicional no era compatible con un civil desmovilizado. De igual manera, se observa que en la jurisdicción ordinaria se sigue un proceso por el delito de concierto para delinquir, por financiar a grupos paramilitares. De allí que surja la dicotomía en el caso, del cual se analiza el escenario a continuación.

\subsubsection{Escenario realizable}

En consecuencia, con respecto al escenario de exclusión de Zuluaga Lindo se puede plantear que dicha condición -de civil- no implica que no sea partícipe del conflicto armado colombiano; pues al respecto, se encuentra como un tercero financiador de grupos paramilitares a través del narcotráfico, calidad que corresponde al ámbito personal de aplicación de la Jurisdicción Especial para la Paz. Se encuentra entonces que: 


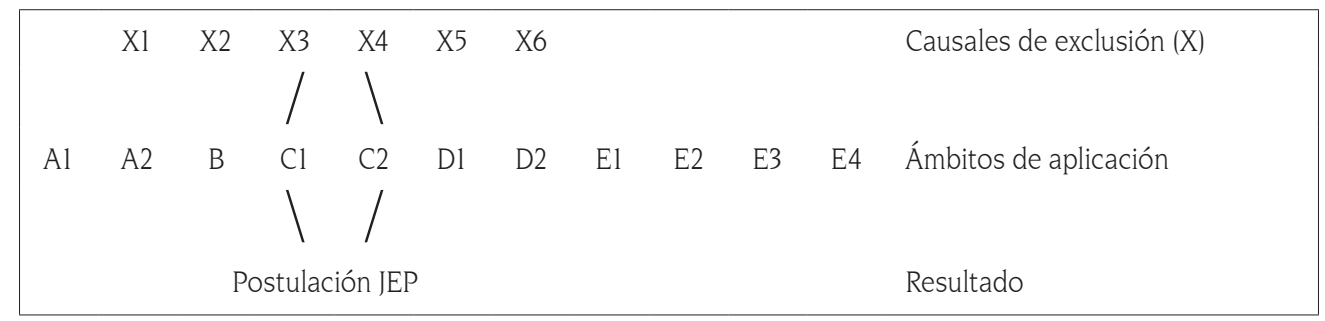

Elaboración propia con base en la cadena de razonamiento planteada por Vargas (2017)

Ello como consecuencia de:

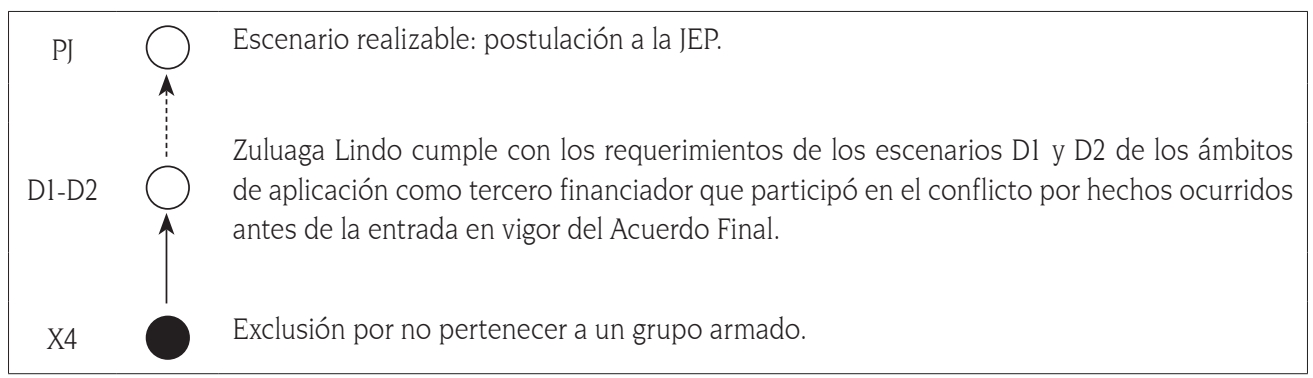

Elaboración propia con base en la cadena de razonamiento planteada por Vargas (2017)

\subsection{Escenario N.․ 2. Postulados excluidos del sistema de Justicia y Paz por incumplimiento de los compromisos adquiridos con la jurisdicción}

A diferencia del escenario anterior, en el que el Congreso al expedir la Ley de Justicia y Paz planteó que el sistema de justicia de transicional era solamente aplicable a aquellos miembros que han pertenecido a grupos al margen de la ley, en este escenario se estudia la exclusión por el incumplimiento de las obligaciones del postulado dentro del proceso penal. Se hace referencia a las obligaciones de verdad, justicia, reparación y no repetición. En ese orden de ideas, cuando se efectuaron las postulaciones al proceso, se comenzaron a presentar problemas con respecto a la colaboración con la verdad por parte de varios postulados, a costa de gozar de los beneficios de la norma, en la práctica no aportaban nada relevante para el esclarecimiento de la verdad procesal, la verdad real y la verdad histórica.

De esta manera se observa en las sentencias de exclusión por el incumplimiento de las obligaciones de los postulados, la renuencia a contribuir al esclarecimiento de los hechos; la colaboración con las autoridades es esencial, y frente a las víctimas, no se trata solamente de contarles relatos, sino de poder establecer un testimonio que permita, si es el caso, cerrar el ciclo que se abrió con la pérdida de familiares o el desplazamiento de sus territorios de origen.

Por otro lado, uno de los problemas que contribuyeron a las exclusiones en el proceso fue que los postulados conti- 
nuaron sus actividades delictivas desde los centros penitenciarios en los que se encontraban recluidos. El resultado fue la extradición de varios postulados, en especial, los comandantes de la mayoría de los bloques de las autodefensas. Así las cosas, se hace necesario observar que el incumplimiento de las obligaciones es causal de exclusión, el cual fue solamente posible con la modificación a la ley 975 de 2005. Para analizar el escenario de manera concreta, se revisa el caso de Rodrigo Tovar Pupo.

El postulado fue excluido de Justicia y Paz por el incumplimiento de las obligaciones adquiridas dentro de dicho sistema de justicia transicional a partir de su desmovilización del Bloque Norte de las Autodefensas Unidas de Colombia (Tribunal Superior de Distrito Judicial de Barranquilla, 2015). La Fiscalía General de la Nación, una vez iniciada la investigación, se encontró frente a la dificultad de que el postulado era renuente a presentarse en las diligencias de versión libre, como a su vez, la dificultad para continuar con la imputación de cargos por las dilaciones en el proceso. Por estas razones, una vez expedida la Ley 1592 de 2012, el ente acusador presentó el 10 de febrero de 2014 la solicitud de exclusión del postulado argumentando su petición en el numeral 1 del artículo 5 (Xl) de la mencionada ley que refiere a la renuencia a comparecer al proceso (cancelación continua de las audiencias de versión libre), lo que conlleva el incumplimiento de los compromisos adquiridos al someterse a dicha jurisdicción.
Para la Fiscalía, el postulado, reconocido como comandante del Bloque Norte de las autodefensas, debía ser excluido de los beneficios de la Ley de Justicia y Paz por no colaborar con el sistema, en especial en lo concerniente a contar la verdad sobre delitos como homicidio (masacres), desaparición, desplazamiento, parapolítica, entre otros (X1).

Como corolario se tiene que la exclusión de este sistema se dio en dos partes: el primero por parte del Tribunal Superior de Distrito Judicial de Barranquilla y el segundo en la Corte Suprema de Justicia. Sobre el primero, el Tribunal Superior de Distrito Judicial de Barranquilla (2015) afirmó que la postulación de Pupo Tovar a la Ley de Justicia y Paz se dio conforme al derecho porque los elementos probatorios permitieron determinar que el procesado era el comandante del Bloque Norte de las autodefensas y que hubo relación con los hermanos Castaño Gil y con otros paramilitares como Mancuso. Sin embargo, su colaboración en el proceso fue discutible, teniendo en cuenta las versiones libres rendidas por los demás postulados, sumado a que, por dilaciones atribuidas al investigado, se retrasó la imputación y que objetivo de verdad, justicia, reparación y no repetición no fue atendido puesto que canceló múltiples audiencias de versión libre, con lo cual desconoció sus compromisos con la Fiscalía y con las víctimas. De allí que el Tribunal accediera a la petición de la Fiscalía y resolviera la exclusión de Tovar Pupo de los beneficios del mencionado sistema de justicia transicional. Por su parte, la Corte Suprema 
de Justicia (2015) ratificó la posición del Tribunal en la medida en que Tovar Pupo, al no cumplir con su carga, debía continuar siendo investigado y juzgado por la jurisdicción ordinaria.

\subsubsection{Escenario realizable}

De lo anterior se puede plantear que la exclusión de Tovar Pupo se da por no cumplir con los compromisos estipulados en la Ley 975 de 2005 que hacen referencia a la colaboración con el sistema en cuanto a la verdad, justicia y reparación. Sin embargo, si el ex paramilitar considerara someterse a la Jurisdicción Especial para la Paz, se considera lo siguiente: lo primero es que puede presentarse como miembro de un grupo armado al margen de la ley y no como un civil participante del conflicto, teniendo en cuenta que las Autodefensas Unidas de Colombia fueron partícipes del conflicto; se plantea entonces:

\begin{tabular}{|llllllllllll}
\hline & X1 & X2 & X3 & X4 & X5 & X6 & & & & & Causales de exclusión (X) \\
No Postulación & & & & & & & & & & & \\
\hline
\end{tabular}

Elaboración propia con base en la cadena de razonamiento planteada por Vargas (2017).

Ello como consecuencia de:

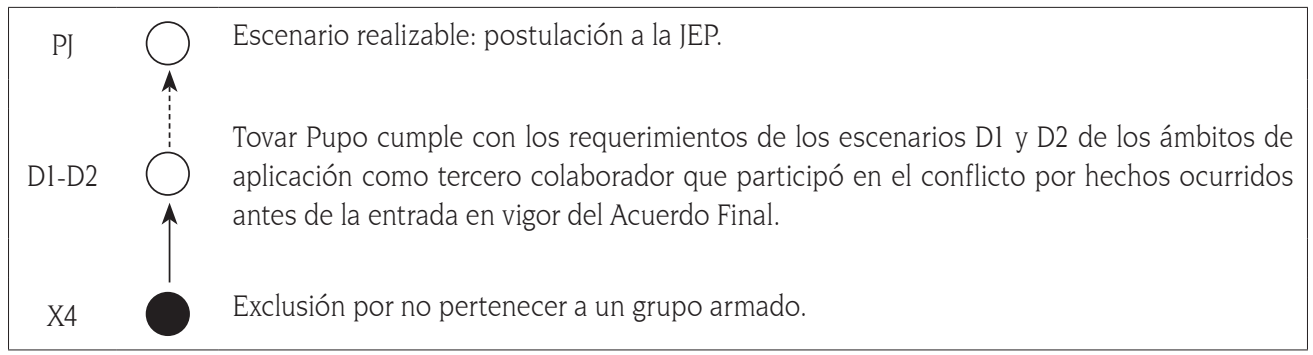

Elaboración propia con base en la cadena de razonamiento planteada por Vargas (2017)

En el caso específico de Tovar Pupo se hace necesario plantear que se pudo dar una postulación por medio de los escenarios A1 y A2, en los cuales en principio deberían estarán englobados los actores del conflicto propiamente dicho, pero que, por parámetros de la negociación de La Habana, las estipulaciones contempladas en el Acuerdo Final y la normatividad respectiva, quedó restringido a los ex miembros de las FARC-EP.

\subsection{Escenario N. ${ }^{\circ}$ 3. Postulados excluidos de Justicia y Paz por continuar con el actuar delictivo una vez sometido a la jurisdicción}

En el escenario anterior se mencionaba que parte del problema de los postulados 
fue la continuación del actuar delictivo, al punto de ser partícipes de la transformación de los grupos paramilitares en bandas criminales dedicadas al negocio del narcotráfico y con objetivos distintos a sus predecesores. En ese sentido, se debe observar que la continuación de los delitos cometidos supone la continuación de su actuar dentro del mismo conflicto armado, toda vez que la comisión de estos implicó la violación de derechos humanos, del derecho internacional humanitario, la consecución de masacres, asesinatos de líderes sociales, amenazas y declaratorias de objetivo militar a personas que manifestaran oposición y rechazo, sin contar el desplazamiento forzado.

De esta manera, en este escenario se pretende mostrar la posibilidad de que una persona se pueda someter a la Jurisdicción Especial para la Paz luego de haber sido excluida de Justicia y Paz por el incumplimiento de sus obligaciones con dicho sistema, por continuar el actuar delictivo. Es de anotar que la mayoría de los postulados que fueron excluidos, fueron extraditados a los Estados Unidos por ser requeridos para responder por el delito de narcotráfico. Así las cosas, se analiza el caso de Daniel Rendón Herrera.

El procesado se postuló para los beneficios de justicia y paz una vez se desmovilizó del Bloque Elmer Cárdenas de las Autodefensas. Sin embargo, al no comparecer a las diligencias de versión libre, por solicitud del entonces Ministerio del Interior y Justicia, se solicitó el retiro de Rendón Herrera de Justicia y Paz (X1), así como también, por las continuas denuncias en los medios de comunicación en la que se indicaba que el postulado continuaba con su actuar delictivo (X5).

Ahora bien, como para el 2008 no existían de manera taxativa las causales de exclusión de los beneficios de la Ley de Justicia y Paz, el Tribunal Superior de Distrito Judicial de Bogotá (2008) se declaró inhibida para pronunciarse al respecto, decisión que fue apelada ante la Corte Suprema de Justicia (2009b) que ordenó al Tribunal que se pronunciara de fondo sobre la solicitud de exclusión. En ese sentido, el Tribunal (2009) ante la renuncia expresa de Rendón Herrera de continuar en Justicia y Paz, se declaró inhibida para pronunciarse sobre la solicitud, dejó así la carga en manos de la Fiscalía para que remitiera la investigación a la jurisdicción ordinaria.

No obstante, el postulado fue posteriormente capturado y desde ese momento manifestó que deseaba continuar con los beneficios de justicia transicional, comenzaron las diligencias de versión libre. Transcurrido el proceso, el Ministerio Público solicitó la viabilidad de la exclusión del postulado considerando la evidencia de la continuación del actuar delictivo del postulado (X5), solicitud que fue coadyuvada por la Fiscalía.

De esta manera, el Ministerio Público soportó la solicitud de la Fiscalía y solicitaron la exclusión de Rendón Herrera por el incumplimiento de los compromisos adquiridos en la Ley de Justicia y Paz, en especial el contenido del artículo 11 de la citada ley de cesar toda actividad 
ilícita, en virtud de las evidencias que mostraban la continuación de la comisión de las conductas punibles por parte del procesado, a saber, por la creación de bandas criminales emergentes dedicadas al narcotráfico como las Águilas Negras, sumado a los vínculos con la oficina de Envigado.

Como corolario se tiene que la exclusión de este sistema se dio en dos partes: el primero por parte del Tribunal Superior de Distrito Judicial de Bogotá y el segundo por la Corte Suprema de Justicia. Sobre el primero, la postulación de don Mario a la Ley de Justicia y Paz se da conforme al derecho porque los elementos probatorios permiten determinar que el procesado pertenecía al bloque Elmer Cárdenas de las autodefensas (Tribunal Superior de Distrito Judicial de Bogotá, 2013). Sin embargo, se observa que su obligación en el proceso es incumplida, si se tiene en cuenta la inasistencia a las diligencias de versión libre y la creación de nuevos grupos armados conocidos como bandas criminales emergentes (bacrim), con lo cual desconoció sus compromisos con la Fiscalía y con las víctimas.

De allí que el Tribunal accedió a la petición del Ministerio Público coadyuvada por la Fiscalía y resolvió la exclusión de Rendón Herrera de los beneficios del mencionado sistema de justicia transicional. Por su parte, la Corte Suprema de Justicia (2014), en concepto sobre la solicitud de extradición por parte del gobierno de los Estados Unidos para que el investigado compareciera ante su sistema por el delito de narcotráfico, ratificó la posición del Tribunal en la medida que don Mario, al no cumplir con su carga, debía continuar siendo investigado y juzgado por la jurisdicción ordinaria y ser extraditado, al no pertenecer al sistema de justicia transicional.

\subsubsection{Escenario realizable}

En virtud de ello, se observa que la exclusión de Rendón Herrera se da por no cumplir con los compromisos estipulados en la Ley 975 de 2005. Sin embargo, si el ex paramilitar considerara someterse a la Jurisdicción Especial para la Paz, se considera lo siguiente:

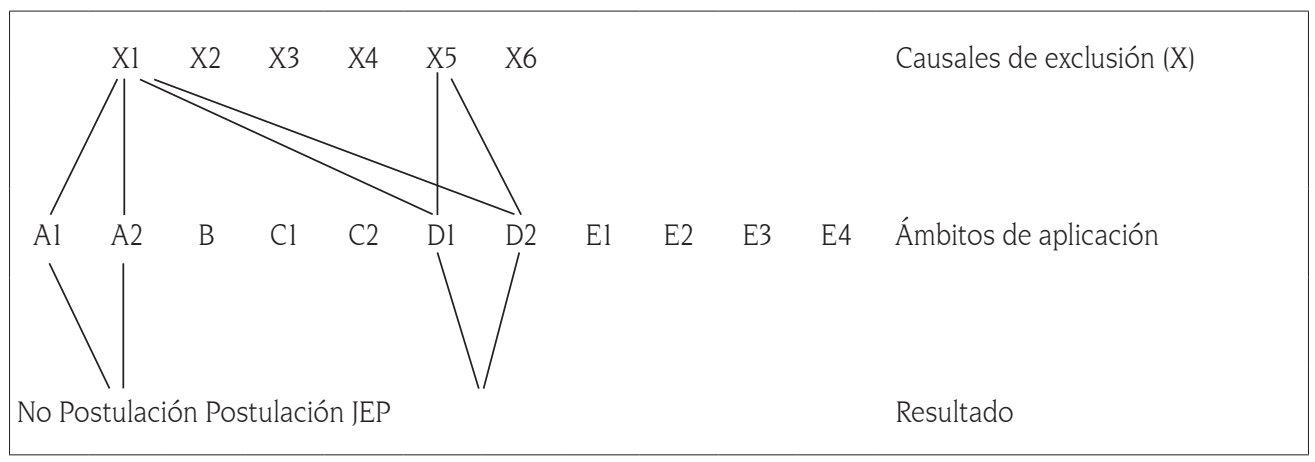

Elaboración propia con base en la cadena de razonamiento planteada por Vargas (2017). 
Ello como consecuencia de:

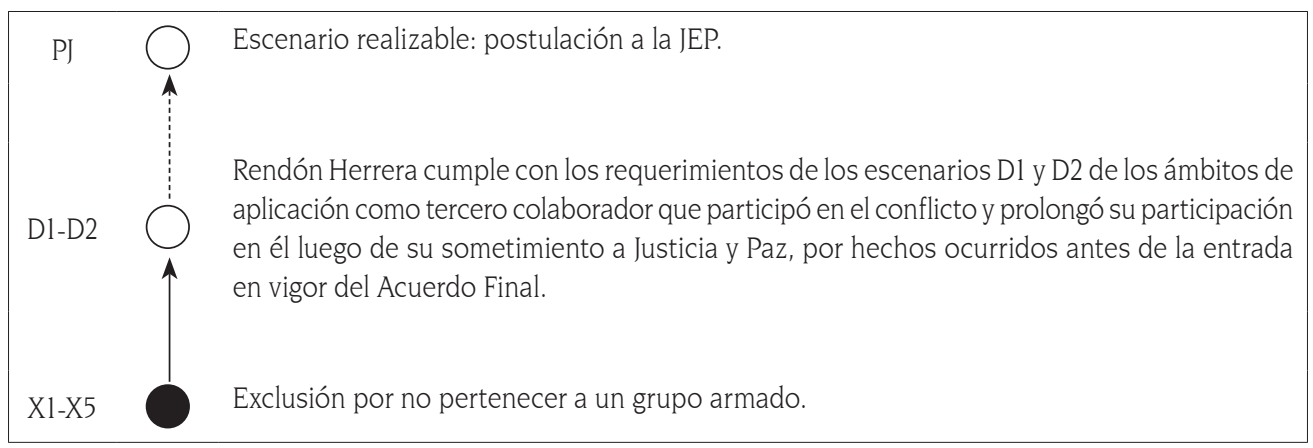

Elaboración propia con base en la cadena de razonamiento planteada por Vargas (2017).

\section{CONCLUSIONES}

La justicia transicional se ha convertido en uno de los elementos más importantes para la reconstrucción de la sociedad colombiana con miras a la superación del conflicto armado. Así, esta está constituida por un conjunto de procesos de transformación social y política profunda en los cuales es necesario utilizar mecanismos judiciales o extrajudiciales. En ese sentido, el primer intento de justicia transicional en Colombia fue la Ley 975 de 2005 conocida como Ley de Justicia y Paz que se dio en virtud del Acuerdo de Ralito entre las Autodefensas Unidas de Colombia y el Gobierno de Colombia. Posteriormente, con la expedición de la Ley 1592 de 2012 se generó la posibilidad de que los miembros que no cumplieran los requisitos o no cumplieran los compromisos pudieran ser excluidos de los beneficios de la Ley de Justicia y Paz. Más adelante apareció la Jurisdicción Especial para la Paz como resultado del Acuerdo de Paz entre las FARC-EP y el Gobierno colombiano.
Ahora bien, tras la constitución de la Jurisdicción Especial para la Paz, surge la incógnita sobre quiénes se podrían postular a este nuevo sistema de justicia transicional; y por ende, sobre la situación de aquellos que fueron excluidos del sistema de Justicia y Paz. Se encontró entonces, tras el establecimiento de un único escenario deseable, bajo la mira de los principios y ámbitos de aplicación de la Ley 1820 de 2016, la posibilidad de tres distintos escenarios realizables para la postulación de excluidos del sistema de Justicia y Paz, al sistema derivado del Acuerdo Final con las FARC-EP.

En ese sentido, en la construcción de los escenarios se tiene que, en el primer supuesto, no es posible presentarse ante la Jurisdicción Especial para la Paz como un actor armado, como quiera que el ex combatiente no ostenta la calidad de miembro de una organización paramilitar, sino un financiador de las Autodefensas Unidas de Colombia como narcotraficante, por lo que en un primer momento 
no podría someterse a esta jurisdicción y debe continuar siendo investigado y juzgado por la jurisdicción ordinaria. Sin embargo, si se tiene en cuenta que el procesado se pueda presentar como civil que financió grupos al margen de la ley en medio del conflicto, es posible que pueda ser admitido en la Jurisdicción Especial para la Paz.

Con respecto al segundo escenario se observó que si bien el procesado fue excluido por no cumplir con sus obligaciones adquiridas, refiriéndose a la renuencia para contribuir a la verdad, justicia, reparación y no repetición, lo cierto es que si la persona se comprometiera a construir la verdad histórica, confesar los crímenes cometidos y reparar a las víctimas, podría ser admitido en la Jurisdicción Especial para la Paz, toda vez que el procesado fue un "cabecilla" de las Autodefensas Unidas de Colombia.

Finalmente, el tercer escenario permite sugerir que el postulado puede ser admitido en la Jurisdicción Especial para la Paz, toda vez que los delitos cometidos, no se pueden considerar como hechos aislados o nuevos que no se encuentran relacionados con el conflicto, sino que, por el contrario, la creación de las bandas criminales emergentes resultan ser la evolución de los grupos paramilitares que hoy por hoy siguen siendo una de las partes que involucra el conflicto armado en Colombia y que hacen que el mismo no termine por completo para dar paso a la paz en el país.
Así las cosas, los escenarios construidos permiten dilucidar que las personas excluidas de Justicia y Paz sí pueden ser admitidas en la Jurisdicción Especial para la Paz, en la medida en que cumplan los requisitos establecidos en la ley, aun cuando no se refiera a ellos de manera directa, sino solamente a los miembros de las FARC-EP y los agentes del Estado colombiano, atendiendo que esta jurisdicción se crea con el fin de investigar y juzgar los crímenes cometidos por los actores del conflicto y los eventuales postulados (como los examinados en los casos), pertenecieron a estructuras ilegales determinantes en la lucha armada. Por otro lado, los escenarios presentados permiten que los magistrados de la JEP tengan un criterio general para admitir o no a los eventuales postulados provenientes de grupos armados distintos de las FARC-EP.

\section{REFERENCIAS}

Abuchaibe, H. (2010). La Declaración del Milenio y la justicia transicional en Colombia. Revista Oasis, (15), 301-314. Recuperado de: https:// revistas.uexternado.edu.co/index.php/oasis/ article/view/3174

Ambos, K. (2009). El marco jurídico de la justicia de transición. En K. Ambos, E. Malarino y G. Elsner (Eds.), Justicia de Transición. Informes de América Latina, Alemania, Italia y España (pp. 23-129). Uruguay: Konrad Adenauer Stiftung. Recuperado de https://www.kas.de/c/document_library/ get file?uuid =c6012f10-4557-5aa7-12dccac8ef7c350fEgroupId $=252038$

Ambos, K., Malarino, E., Elsner, G. (Eds.). (2009). Justicia de Transición. Informes de América Latina, Alemania, Italia y España. Uruguay: 
Konrad Adenauer Stiftung. Recuperado de https://www.kas.de/c/document_library/ get file?uuid=c6012f10-4557-5aa7-12dccac8ef7c350fEgroupId $=252038$

Benavidez, F. (2010). Justicia en épocas de transición: conceptos, modelos, debates y experiencias. Bogotá, D.C.: Grupo Editorial Ibáñez.

Bergsmo, M., y Saffon, M. (2011). Enfrentando una fila de atrocidades pasadas: ¿cómo seleccionar y priorizar casos de crímenes internacionales centrales? En: L. Ambos (Coord.), Selección y priorización como estrategia de persecución en los casos de crímenes internacionales (pp. 23 - 112). Bogotá D.C.: Deutsche Gesellschaft für Internationale Zusammenarbeit (GIZ) GmbH.

Cely, A. (1999). Metodología de los escenarios para estudios prospectivos. Revista de Ingeniería e Investigación, (44), 26-35. Recuperado de: https://revistas.unal.edu.co/index.php/ ingeinv/article/view/21296/22265

Congreso de la República (2005, julio 25). Ley 975 de 2005. Por la cual se dictan disposiciones para la reincorporación de miembros de grupos armados organizados al margen de la ley, que contribuyan de manera efectiva a la consecución de la paz nacional y se dictan otras disposiciones para acuerdos humanitarios. Diario Oficial (45.980) Recuperado de http://www.secretariasenado.gov.co/senado/ basedoc/ley_0975_2005.html

Congreso de la República (2012, diciembre 3). Ley 1592 de 2012. Por medio de la cual se introducen modificaciones a la Ley 975 de 2005. Por la cual se dictan disposiciones para la reincorporación de miembros de grupos armados organizados al margen de la ley, que contribuyan de manera efectiva a la consecución de la paz nacional y se dictan otras disposiciones para acuerdos humanitarios y se dictan otras disposiciones. Diario Oficial
(48.633). Recuperado de https://www.ictj.org/ sites/default/files/subsites/colombia-lineatiempo/docs/Ley975/Ley1592.pdf

Congreso de la República. (2016, diciembre 30). Ley 1820 de 2016. Por medio de la cual se dictan disposiciones sobre amnistía, indulto y tratamientos penales especiales y otras disposiciones. Diario Oficial (50.102). Recuperado de http://www.secretariasenado. gov.co/senado/basedoc/ley_1820_2016. $\underline{\mathrm{html}}$

Congreso de la República. (2017). Proyecto de Ley Estatutaria de la Administración de Justicia en la Jurisdicción Especial para la Paz. Recuperado de: http://dacn.mininterior.gov.co/sites/default/ files/noticias/proyecto_de_ley_estatutaria _de_la_administracion _de _justicia_en _la_jurisdiccion_especial _ para_la_paz.pdf

Congreso de la República (2017, abril 4). Acto Legislativo 01 de 2017. Por medio del cual se crean un título de disposiciones transitorias de la Constitución para la terminación del conflicto armado y la construcción de una paz estable y duradera y se dictan otras disposiciones. Diario Oficial (48.633). Recuperado de https://www.alcaldiabogota. gov.co/sisjur/normas/Normal.jsp?i=50829

Coral, J., y Castillo, M. (2011). John Rawls y las bases para la construcción de la sociedad civil. Papel Político, 16(2), 515-528. Recuperado de: http://www.redalyc.org/articulo. oa?id $=77722772008$

Corte Constitucional. Sentencia C-836. (9 de agosto de 2001). [MP Rodrigo Escobar Gill.

Corte Constitucional. Sentencia C-004. (20 de enero de 2003-A). [MP Eduardo Montealegre Lynett].

Corte Constitucional. Sentencia C-871. (30 de septiembre de 2003). [MP Clara Inés Vargas Hernández]. 
Corte Constitucional. Sentencia C-131. (19 de febrero de 2004). (MP Clara Inés Vargas Hernández].

Corte Constitucional. Sentencia T-956. (15 de diciembre de 2011). (MP Jorge Iván Palacio Palacio].

Corte Constitucional. Sentencia C-579. (28 de agosto de 2013-A). (MP Jorge Ignacio Pretelt Chaljub].

Corte Constitucional. Sentencia C-752. (30 de octubre de 2013-B). [MP Luis Guillermo Guerrero Pérez].

Corte Constitucional. Sentencia C-694. (11 de noviembre de 2015). [MP Alberto Rojas Ríos].

Corte Constitucional. Sentencia C-007. (1 de marzo de 2018). [MP Diana Fajardo Rivera].

Corte Suprema de Justicia. Sala Penal. Sentencia Exp. 30998. (12 de febrero de 2009-A). [MP Sigifredo Espinosa Pérez].

Corte Suprema de Justicia. Auto 31162. (11 de marzo de 2009-B). (MP Julio Enrique Socha Salamancal.

Corte Suprema de Justicia. Sala Penal. Sentencia Exp. 31539. (31 de julio de 2009-C). [MP Augusto Ibáñez Guzmán].

Corte Suprema de Justicia. Sala Penal. Sentencia Exp. 39162. (22 de agosto de 2012). [MP Fernando Alberto Castro Caballero].

Corte Suprema de Justicia. Auto No. AP501-2014. 12 de febrero de 2014-A). (MP Gustavo Enrique Malo Fernández].

Corte Suprema de Justicia. Concepto No. CP1882014. (12 de noviembre de 2014-B). [MP Eugenio Fernández Carlier].

Corte Suprema de Justicia. Auto AP4710-2015. (19 de agosto de 2015). (MP Eugenio Fernández Carlier].
Corte Suprema de Justicia. Sala Penal. Sentencia Exp. 14206. (5 de octubre de 2016). [MP Luis Antonio Hernández Barbosa].

Corte Suprema de Justicia. Auto No. AP2445-2017. (19 de abril de 2017-A). [MP Luis Antonio Hernández Barbosa].

Corte Suprema de Justicia. Auto No. AP2789-2017. (3 de mayo de 2017-B). [MP Fernando Alberto Castro Caballero].

Corte Suprema de Justicia. Auto No. AP3713-2017. (7 de junio de 2017-C). [MP Luis Guillermo Salazar Otero].

Gómez Sánchez, G. (2014). Justicia transicional en disputa: una perspectiva constructivista sobre las luchas por la verdad, la justicia y la reparación en Colombia. Medellín. Universidad de Antioquia.

López, C., González, D., y Errandonea, J. (2012) Justicia transicional en Colombia. En A. Forer y C. López (Eds), Colombia: un nuevo modelo de justicia transicional (pp. 11-114). Bogotá, Colombia: Deutsche Gesellschaft für Internationale Zusammenarbeit (GIZ). Recuperado de

López, D. (2010) Recomendaciones para la elaboración de estrategias de priorización de casos en el marco de la Ley de Justicia y Paz. International Law: Revista Colombiana de Derecho Internacional, 8(17), 63-86. Recuperado de: http://revistas.javeriana.edu.co/index.php/ internationallaw/article/view/13820

Londoño, L., y Marín, J. (2002). Metodología de la investigación holística: Una propuesta integradora desde las sociedades fragmentadas. Uni-pluri/versidad, 2(3), 22-23. Recuperado de: https://aprendeenlinea.udea.edu.co/revistas/ index.php/unip/article/view/12229/11094

Maqueda, J. (1996). Cuadernos de dirección estratégica y planificación. Madrid, España: Ediciones Díaz de Santos. 
Mejía, O. (1998). Justicia y democracia consensual. Bogotá, Colombia: Siglo del Hombre Editores.

Osorio, R. (2017). Paz o desmovilización: Justicia transicional, indultos, amnistías, perdones judiciales y posconflicto. Revista de la Facultad de Derecho y Ciencias Políticas, 47(126), 55-74. Recuperado de: http://www. scielo.org.co/pdf/rfdcp/v47n126/0120-3886rfdcp-47-126-00055.pdf

Patiño Yepes, A. (2010). Las reparaciones simbólicas en escenarios de justicia transicional. Revista Latinoamericana de Derechos Humanos, 21(2), 51-61. Recuperado de: http://www.revistas.una.ac.cr/index.php/derechoshumanos/ article/view/1928

Posada, J. (2010). Elementos fundamentales de la hermenéutica jurídica. Nuevo Derecho, 5(6), 47-63. Recuperado de: http://revistas.iue.edu. co/index.php/nuevoderecho/article/view/262

Quinche, M. (2009). Los estándares de la Corte Interamericana y la Ley de Justicia y Paz. Bogotá, D.C.: Universidad del Rosario.

Ramírez, J. (2010). Thomas Hobbes y el Estado absoluto: del Estado de razón al Estado de terror. Medellín: Universidad de Antioquia.

Rúa, C. (2014). Prolegómenos para la aplicación de los criterios de priorización de delitos en los procesos de justicia y paz en Colombia. Revista Latinoamericana de Derechos Humanos, 25(2), 193-220. Recuperado de: http://www. revistas.una.ac.cr/index.php/derechoshumanos/article/view/6159/6142

Rúa, C. (2015). Los momentos de la justicia transicional en Colombia. Revista de Derecho, (43), 71-109. http://dx.doi.org/10.14482/ dere. 43.6270

Rúa, C. (2016). La justicia anamnética como construcción complementaria al paradigma de justicia transicional. Una mirada desde el caso colombiano. Revista Ius et Praxis, 22(1),
455-492. Recuperado de: https://scielo. conicyt.cl/pdf/iusetp/v22n1/art13.pdf

Rúa, C. (2018). El campo de la justicia transicional. Universum, 33(1), 187-210. Recuperado de: https://www.academia.edu/37264200/ Carlos_Felipe_R\%C3\%BAa_Delgado _ EL_CAMPO _ DE_LA_JUSTICIA_TRANSICIONAL

Rúa, C., y Castillo, M. (2015). El principio de transparencia en el Estado Social de Derecho: una revisión de la legitimidad política. Cali: Editorial Bonaventuriana.

Seils, P. (2012). Propuesta de criterios de selección y priorización para la ley de Justicia y Paz en Colombia. Centro Internacional para la Justicia Transicional. Análisis, 1-12. Recuperado de: https://www.ictj.org/sites/default/files/ ICTJ-COL-PaulSeils-Propuesta\%20de\%20 criterios\%20de\%20selecci\%C3\%B3n\%20 y\%20priorizaci\%C3\%B3n-2012.pdf

Teitel, R. (2002). Genealogía de la justicia transicional. Harvard Human Rights Journal, 16, 69-94. Recuperado de: http://biblioteca.cejamericas. org/bitstream/handle/2015/2059/Teitel_Genealogia. pdf? sequence $=1$ EisAllowed $=y$

Teitel, R. (2017). Justicia transicional. Bogotá: Universidad Externado de Colombia.

Tribunal Superior de Distrito Judicial de Bogotá. Sala de Justicia y Paz. (28 de agosto de 2008). Auto No. 2007-83019.

Tribunal Superior de Distrito Judicial de Bogotá. Sala de Justicia y Paz. (18 de mayo de 2009). Auto No. 2007-83019.

Tribunal Superior de Distrito Judicial de Bogotá. Sala de Justicia y Paz. (9 de septiembre de 2013-). Auto No. 2007-83019.

Tribunal Superior de Distrito Judicial de Medellín. Sala de Justicia y Paz. (17 de septiembre de 2013). Auto No. 2006-80605. 
Tribunal Superior de Distrito Judicial de Barranquilla. Sala de Justicia y Paz. (22 de junio de 2015). Auto No. 2014-80015.

Unidad Nacional de Fiscalías para la Justicia y la Paz. (2013). Plan de Acción de casos a priorizar por la Unidad Nacional de Fiscalías para la Justicia y la Paz. Recuperado de: http://www.fiscalia.gov. co/jyp/wp-con-tent/uploads/\%202012/04/ Plan-de-Accion-de-Priorizacion-de-laUnidad.pdf
Valdivieso, A. (2012). La justicia transicional en Colombia. Los estándares internacionales de derechos humanos y derecho internacional humanitario en la política de Santos. Revista Papel Político, 17(2), 621-653. Recuperado de: http://revistas.javeriana.edu.co/index.php/ papelpol/article/view/6545

Vargas, O. (2017). Lo probable y lo demostrable. En Memorias XXXVIII Congreso de Derecho Procesal. Bogotá D.C.: Instituto Colombiano de Derecho Procesal. 